\title{
An Investigation of the Linkage between Relationship Status (Single vs. Partnered), Identity Dimensions and Self-construals in a Sample of Polish Young Adults
}

\begin{abstract}
The aim of this exploratory cross-sectional study was to examine the associations among relationship status, identity processes, and self-construals among Polish young adults.

The theoretical framework of the study consisted of Erikson's psychosocial theory of human development (Erikson, 1963; 1968; 1980), the dual-cycle model of identity formation (Luyckx, Goossens, \& Soenens, 2006), and the concept of independent and interdependent self-construals. A total of 291 university students (155 females and 136 males) aged 20-25 completed the Dimensions of Identity Development Scale (DIDS; Luyckx, Schwartz et al., 2008) (Polish adaptation - Brzezińska \& Piotrowski, 2010a) and Self-Construal Scale (SCS; Singelis, 1994) (Polish adaptation - Pilarska, 2014). Results showed that single individuals scored higher on exploration in breadth, exploration in depth, and ruminative exploration, and lower on commitment making and identification with commitment than did partnered individuals. Further, single and partnered individuals did not differ in the area of independent and interdependent self-construals. Discriminant function analysis revealed that especially ruminative exploration and exploration in breadth were important variables for discriminating single from partnered status.
\end{abstract}

Key words: dual-cycle model of identity formation, independent self-construal, interdependent self-construal, single, partnered, young adults

\section{Introduction}

Major changes in the transition to adulthood during the last 50 years in many Western countries, including Poland, led to a variety of less formalized and more individualized life paths into adulthood (Brzezińska, Kaczan, Piotrowski, \& Rękosiewicz, 2011; Lehnart, Neyer, \& Eccles, 2010). This variety of life paths includes, among others, alternative forms of marital and family life such as singlehood, living apart together, and cohabitation without marriage (Lehnart et al., 2010; Slany, 2006). However, despite this contemporary heterogeneity of marital and family life, establishing a close, intimate bond with a romantic partner still constitutes one of the most prominent developmental tasks for young adults (Erikson, 1980; Rauer, Pettit, Lansford, Bates, \& Dodge, 2013). Despite that many young adults are committed to romantic relationships or have had experience with them (Carver, Joyner, \& Udry, 2003), many young adults find it difficult to establish secure and well-functioning intimate relationships (Collins, Cooper, Albino, \& Allard, 2002). In Europe and in the United States of America, the number of single persons has risen substantially in the past decades, and this trend will likely continue in these regions (Poortman \& Liefbroer, 2010). This trend is evident in Poland as well (SuchPyrgiel, 2014), the country where the present study was conducted. Therefore, due to the contemporary diversity in the domain of marital life forms, it is valuable to compare single individuals with individuals in nonmarital romantic relationships as relationships play a crucial role in young adults' lives (Simon \& Barrett, 2010).

To understand how young adults engage themselves in romantic relationships and the role such relationships play in daily life, it is important to focus on individuals'

\footnotetext{
* Adam Mickiewicz University in Poznań, Institute of Psychology, Poland

** Faculty of Psychology and Educational Sciences, KU Leuven, Leuven, Belgium
} 
identity and self-construals. First, identity and intimacy are acknowledged to constitute two criteria for achieving psychological maturity in young adulthood (Erikson, 1968; Winefield \& Harvey, 1996). According to Erikson (1968), the true "engagement" with others requires a firm selfdelineated identity, and an established identity prepares an individual to make and sustain interpersonal commitments (Markstrom \& Kalmanir, 2001). Recent studies indeed have confirmed the role of a strong sense of identity for achieving satisfying committed relationships in adulthood (e.g., Zimmer-Gembeck \& Petherick, 2006). Further, identity processes have been found to play an important role in the initiation, maintenance, and dissolution of intimate relationships in late adolescence and young adulthood (e.g., Klimstra et al., 2012). Interestingly, although the subjects of identity and self-construals have been widely investigated - also by Polish researchers (e.g., Brzezińska \& Piotrowski, 2010b; Cieciuch, 2010; Senejko, 2010) and Pilarska (2014) respectively - we still lack substantial knowledge about the linkage between identity and self-construals, and young adults' relationship status (single vs. partnered; i.e., possessing a lifetime partner or not). Second, many factors influence the desire to commit in a new relationship, and one of these factors includes the degree to which an individual has defined the self in terms of close relationships (Terzino \& Cross, 2009).

\section{Identity in Young Adulthood}

According to Erikson (1963), the process of identity formation is the central psychosocial developmental task of adolescence and the transition to adulthood. Research has also demonstrated that identity development continues beyond adolescence (Pals, 1999; Schwartz, Côté, \& Arnett, 2005). Erikson (1968, p. 19) perceived identity as a 'subjective sense of an invigorating sameness and continuity'. Identity formation as a key developmental task in late adolescence and the transition to adulthood requires an individual to explore alternatives before he or she will commit to a set of self-defining choices (Marcia, 1966). These two processes - commitment (i.e., choosing a certain option within a life domain) and exploration (i.e., examining different alternatives in a life domain) - became the main dimensions in the identity status paradigm proposed by Marcia $(1966,1980)$. Crossing these exploration and commitment dimensions, Marcia derived the following four identity statuses: achievement (a commitment made following exploration), foreclosure (a commitment adopted without much prior exploration), moratorium (ongoing exploration with little commitment), and diffusion (lack of commitment coupled with little systematic exploration).

Recently, Luyckx, Goossens, Soenens, and Beyers (2006) proposed an extension of the identity status model by differentiating exploration and commitment into two separate dimensions each. This extended model, known as the dual-cycle model of identity formation, includes two cycles of identity formation (Luyckx, Goossens, \& Soenens, 2006). In this model, the first cycle represents
Marcia's (1966) classical paradigm (i.e., being focused on the formation of commitments) and encompasses exploration in breadth and commitment making. The second cycle reflects the more recent views on identity formation (i.e., being focused on the evaluation of commitments; Luyckx, Goossens, \& Soenens, 2006) and encompasses exploration in depth and identification with commitment. In particular, exploration in breadth involves the weighing up of various alternatives and is hypothesized to be an important process preceding commitment making (Luyckx, Goossens, \& Soenens, 2006). Commitment making was defined similarly as Marcia's commitment dimension, that is, as the degree to which adolescents have made choices about important identity-relevant issues (Luyckx, Schwartz, et al., 2008). When the commitment is made, an individual may explore these areas in which he or she has already made commitments in order to evaluate and verify whether these commitments are congruent with his or her standards, expectations, and abilities (a process referred to as exploration in depth). In addition, an important component of identity formation is identification with commitment which refers to the degree to which adolescents feel certain about, can identify with, and internalize their choices (Luyckx, Schwartz, et al., 2008).

Finally, in this model, an additional exploration dimension is included, that is, ruminative exploration. This type of exploration pertains to an individual's concerns and problems experienced in the course of identity exploration (Luyckx, Schwartz, et al., 2008). Moreover, this type of exploration is positively related to distress and to selfrumination. Individuals who score high on this dimension are found to experience problems in gaining satisfactory answers to their identity-related questions, which may result in intrusive feelings such as uncertainty or a sense of being incompetent (Luyckx, Schwartz, et al., 2008).

With respect to the association between identity and relationship status, prior studies were mainly focused on the associations between identity and various models of intimacy (Markstrom \& Kalmanir, 2001). Research using the identity status paradigm basically has confirmed Erikson's theoretical suggestions with respect to the key role of identity for intimacy development (e.g., Fitch \& Adams, 1983; Orlofsky, Marcia, \& Lesser, 1973; Tesch \& Whitbourne, 1982). More specifically, active more mature identity was found to be associated with higher levels of intimacy (Fitch \& Adams, 1983; Orlofsky et al., 1973): individuals in identity achievement also were characterized by higher levels of intimacy in comparison to individuals in other identity statuses. However, other studies (e.g., Tesch \& Whitbourne, 1982) have also found that individuals in less mature identity statuses also reported high levels of intimacy. In more recent studies, Klimstra and colleagues (2012) have found that interpersonal identity processes were better predictors of relational breakups than personality traits were. Furthermore, in a Polish study by Brzezińska and Piotrowski (2010b), participants characterized in achieved or foreclosed identity statuses scored highest on readiness for intimate relationships, whereas participants in moratorium scored lowest on 
readiness for intimate relationships. Moreover, in a Polish study by Palus (2010), the association between relationship status and the identity statutes proposed by Marcia (1966) was investigated by using the Objective Measure of Ego Identity Status (EOM-EIS-2; Bennion \& Adams, 1986). Results indicated that single and partnered individuals did not differ in regard to identity statuses in the ideological and interpersonal domains (Palus, 2010). As such, further research using contemporary identity models is needed to further examine how identity processes are related to relationship status.

\section{Independent and Interdependent Self-Construals}

The self-system is recognized to play an important role in the motivation and regulation of interpersonal processes, and independent and interdependent self-construals are one of the most general and broad self-schemata, and (Markus \& Kitayama, 1991; Pilarska, 2014). These two divergent construals of the self - an independent and interdependent self -differ in regards to the role assigned to the other in one's self-definition. Consequently, these self-construals are characterized by different attributes. Individuals with highly developed independent self-construals emphasize their unique internal attributes, abilities, thoughts, and feelings that separate them from others (Singelis, 1994). However, the interdependent self-construal can be characterized as being embedded in and interconnected with others. Individuals with highly developed interdependent selfconstruals emphasize belonging and fitting; they depend on others and on their relations with others. Good interpersonal relationships are important sources of self-esteem for them (Singelis, 1994).

The degree to which others are included in the self influence not only an individual's cognitions, emotions, and motivations, but also their social relationships (Cross, Bacon, \& Morris, 2000; Cross \& Madson, 1997; Markus \& Kitayama, 1991). Differences in the nature and structure of self-construals may result in different orientations toward relationships with others and different ways of managing relationships (Cross \& Madson, 1997). In particular, variation in relational self-construal was associated with levels of self-disclosure, responsiveness, commitment to a new relationship partner (Terzino \& Cross, 2009). Prior research (e.g., Cross \& Madson, 1997; Gore, Cross, \& Morris, 2006; Markus \& Kitayama, 1991) has supported the assumption that individuals with an interdependent self-construal who primarily define themselves in terms of close relationships may seek to develop and maintain close relationships with others. However, individuals with an independent self-construal tend to maintain their sense of independence, uniqueness, and individuality. Consequently, individuals with a predominantly interdependent self-construal were found to report more people who were very important to them, perceived higher levels of social support, and they described their most important relationships as closer and more committed than did individuals with a low interdependent self-construal (Cross et al., 2000). The individuals with a predominantly interdependent self-construal were also found to exhibit greater self-disclosure (Cross et al., 2000) and invested more strongly in an enduring close relationship (Gore at al., 2006).

\section{The Present Study}

Although identity and self-construals are considered to be associated with different relational outcomes, little attention (but see Klimstra et al., 2012; Palus, 2010) has been given to the role of identity and self-construals in relationship status in young adulthood. To the best of our knowledge, prior research did not focus on relationship status in young adulthood in the context of identity dimensions and self-construals. Due to the general lack of previous research in this area and the exploratory nature of this study, no specific hypotheses were developed. Instead, the purpose of this study was to explore how identity dimensions and self-construals are related to relationship status in young adulthood. In this study we addressed the following two research questions:

Q1. Do single individuals and individuals in nonmarital romantic relationships differ with respect to identity dimensions?

Q2. Do single individuals and individuals in nonmarital romantic relationships differ with respect to selfconstruals?

\section{Methods}

\section{Participants and Procedure}

The study was conducted in a sample of university students from different faculties of Adam Mickiewicz University in Poznan, Poland. Five hundred questionnaires were originally distributed of which 370 were returned. Seventy-nine participants were excluded from the study due to incomplete data or not meeting the inclusion criteria, yielding a final sample of 291 students - 155 females $(53.30 \%)$ and 136 males $(46.70 \%)$. Participants were 20-25 years old $(M=22.29, S D=2.05)$ and resided in a large Polish city with a population exceeding 500,000 inhabitants. All respondents were never married, had no children, and were heterosexual. For the purposes of the study, being single was defined as "not in a nonmarital romantic relationship for at least the past six or more months, but wanting to become committed in the near future (within the next year or so)" (see also Schachner, Shaver, \& Gillath, 2008). In turn, being partnered was defined as "in a nonmarital romantic relationship for at least the past six or more months, and wanting to be committed in the near future (within the next year or so)" (see Schachner et al., 2008). One hundred and thirty seven students $(47.10 \%)$ declared being in a romantic relationship at the time of the assessment while 154 students $(52.90 \%)$ were not.

The first author distributed the measures to the participants across the different courses. The questionnaire packages were administered in classrooms to groups of 20 to 30 students at a time and participation was voluntary. 
The instructions were read aloud. An explanation as to the purpose of the study was given as was an assurance that the information provided would remain anonymous. Participants were also informed that they could resign from the study at any time.

\section{Measures}

Dimensions of Identity Development Scale (DIDS; Luyckx, Schwartz et al., 2008) (Polish adaptation Brzezińska \& Piotrowski, 2010a). It is an instrument designed to measure five identity dimensions. It consists of 25 items (5 items per scale) evaluated on 5-point Likert-type scales ranging from 1 = completely disagree to $5=$ completely agree. It is a reliable instrument with a clear factor structure (Luyckx, Schwartz et al., 2008). In the current study, Cronbach's alphas were estimated to be $.80, .79, .63, .89, .79$ for exploration in breadth, exploration in depth, ruminative exploration, commitment making, and identification in commitment, respectively.

Self-Construal Scale (SCS; Singelis, 1994) (Polish adaptation - Pilarska, 2014). The Self-Construal Scale is a 24-item instrument designed to measure the participant's levels of interdependence and independence. Participants rate themselves on a Likert-type scale ranging from $1=$ strongly disagree to $7=$ strongly agree. The SCS was found to be is a reliable and valid measurement of the independent and interdependent dimensions of self (Singelis, 1994). The Polish-language version of the SCS consisted of 18 items contrary to the original 24-item SCS, due to the fact that the analysis of Cronbach's alphas coefficients indicated to remove items 10, 11, 16, 19, 22, and 25 in order to increase the reliability of the Independent
Self-construal subscale (Pilarska, 2014). In the present study, Cronbach's alphas were .67 for Independent Selfconstrual and .73 for Interdependent Self-construal.

\section{Results}

First, to test whether group differences exist between single individuals and individuals in nonmarital romantic relationships with respect to identity dimensions we performed a one-way multivariate analysis of variance followed up by univariate analyses. Second, in order to test for possible differences between single individuals and individuals in nonmarital romantic relationships with respect to self-construals we performed a one-way multivariate analysis of variance followed up by univariate analyses. Finally, we examined the extent to which identity dimensions and self-construals predicted of relationship status by performing discriminant function analysis.

\section{Relationship Status and Identity Dimensions}

First, to examine possible mean differences between single and partnered samples in regard to identity dimensions a one-way multivariate analysis of variance was used resulting in a significant multivariate effect (Wilks's $\left.\Lambda=.90, F(5,285)=8.84, p=.000, \eta^{2}=.13\right)$.

Follow-up univariate analyses in Table 1 revealed that single individuals scored higher on exploration in breadth, exploration in depth, and ruminative exploration than did individuals in nonmarital romantic relationships. At the same time, single individuals scored lower on commitment making and identification with commitment than did partnered individuals.

Table 1. Means and Standard Deviations on Identity Dimension and Self-construals by Relationship Status

\begin{tabular}{|c|c|c|c|c|c|}
\hline Variable & $\begin{array}{l}\text { Total sample } \\
(N=291)\end{array}$ & $\begin{array}{l}\text { Single sample } \\
\quad(n=154)\end{array}$ & $\begin{array}{l}\text { Partnered sample } \\
\qquad(n=137)\end{array}$ & $F$ ratio & $\eta 2$ \\
\hline & Mean (SD) & Mean (SD) & Mean (SD) & & \\
\hline Multivariate test & & & & $8.84 * * *$ & .13 \\
\hline \multicolumn{6}{|l|}{ Identity Dimensions } \\
\hline Commitment making & $3.96(1.03)$ & $3.69(1.03)$ & $4.27(0.94)$ & $24.38 * * *$ & .08 \\
\hline $\begin{array}{l}\text { Identification with } \\
\text { commitment }\end{array}$ & $4.27(0.73)$ & $4.17(0.71)$ & $4.38(0.73)$ & $6.24 *$ & .02 \\
\hline Exploration in breadth & $4.09(0.83)$ & $4.30(0.77)$ & $3.86(0.83)$ & $21.62 * * *$ & .07 \\
\hline Exploration in depth & $3.89(0.74)$ & $4.03(0.74)$ & $3.74(0.72)$ & $10.78 * *$ & .04 \\
\hline Ruminative exploration & $3.30(0.93)$ & $3.59(0.91)$ & $2.99(0.87)$ & $32.86^{* * *}$ & .10 \\
\hline Multivariate test & & & & .46 & .00 \\
\hline \multicolumn{6}{|l|}{ Self-construals } \\
\hline Independent self & $44.11(7.29)$ & $43.90(6.65)$ & $44.34(7.97)$ & .42 & .00 \\
\hline Interdependent Self & $41.26(6.62)$ & $41.61(6.46)$ & $40.87(6.80)$ & .47 & .00 \\
\hline
\end{tabular}

$* * * p<.001 ; * * p<.01 ; * p<.05$. 


\section{Relationship Status and Self-construals}

Second, to examine possible mean differences between both single and partnered samples in regard to self-construals a one-way multivariate analysis of variance was used resulting in a non-significant multivariate effect (Wilks's $\Lambda=.99), F(2,286)=.46, p=.634, \eta^{2}=0.003$ (see Table 1).

\section{Identity Dimensions and Self-construals as Predictors of Relationship Status}

As recommended (e.g., Field, 2009) the MANOVA was followed up with discriminant analysis (DFA) to examine how the dependent variables discriminate between the single and partnered groups. We employed a twogroup, stepwise discriminant analysis with the maximum significance of $F$ to enter of .05, and minimum significance of $F$ to remove of .10. The analysis revealed one significant discriminant function, Wilks's $\Lambda=.88, \chi^{2}(2)=35.88$, $p=.000$. The eigenvalue of the discriminant function was .13 and the canonical correlation was .34. The variables included into the model were exploration in breadth, $F(1,289)=28.94, p=.007$ and ruminative exploration, $F(1,289)=19.10, p=.008$, whereas exploration in depth, commitment making and identification with commitment, and independent self and interdependent self were removed from the model. Table 2 presents the standardized discriminant function coefficients and the pooled withingroups correlations between discriminating variables and standardized canonical discriminant functions. The loadings $\geq .30$ were considered substantial.

As Table 2 displays, the highest standardized discriminant function coefficient for ruminative exploration revealed that this variable contributed in the highest degree to the distinguishing between single and partnered individuals. Furthermore, the high standardized discriminant function coefficient for exploration in breadth indicated that is also an important variable for a discrimination between single and partnered individuals. Additional and congruent information with the standardized discriminant function coefficients are provided by the pooled within-groups correlations. The correlations between outcomes and the discriminant function revealed that ruminative exploration $(r=.87)$ and exploration in breadth $(r=.75)$ highly loaded onto the function.

The group membership prediction accuracy was measured on the analysis and the holdout sub-samples. The hit ratio for the analysis sample is $64.60 \%$, whereas that for the holdout sample is $63.90 \%$. Both ratios are close with a difference of only $0.07 \%$. To assess the appropriateness of these hit ratios and the classification accuracy for groups, two statistics were employed: the proportional chance criterion and the Press's Q. The proportional chance criterion is the sum of squared proportion of individuals in each group. Since two groups were studied, the proportional chance criterion is calculated as $.50\left(.47^{2}+.53^{2}\right)$. It is suggested that the classification accuracy should be at least one-fourth greater than that is achieved by chance. Using the proportional chance criterion, the acceptable classification accuracy should be at least $.53(.25 * 1.25)$, or $53 \%$. The overall classification accuracy for the analysis and holdout sub-samples is $64.60 \%$ and $63.90 \%$, respectively. Both exceed the threshold of $53 \%$, indicating that the classification results are better than chance. The Press's Q statistic calculated for this study is 24.82 , which is greater than the critical value (6.64) from the Chi-square distribution with 1 degree of freedom at the significance level of .01 . Thus, the predictions were also significantly better than chance. Both the proportional chance criterion and Press's Q statistic indicated that the classification accuracy is satisfactory. Hence, the model investigated has good predictive power. With a canonical correlation of .34, it can be concluded that $11.56 \%$ (square of the canonical correlation, $R^{2}=11.56$ ) of the variance in the dependent variable was accounted for by this model.

\section{Discussion}

Young adults are expected to undertake new social roles such as engaging in a romantic relationship (LodiSmith \& Roberts, 2007). In achieving such roles, a coherent sense of identity plays a key role (Erikson, 1968; Fadjukoff, Pulkkinen, \& Kokko, 2005). The self may play a significant role in the area of romantic relationships because it is an important regulator of many human functioning's aspects (Markus \& Kitayama, 1991; Pilarska, 2014). It also influences the motivation to develop and maintain close relationships (Gore et al., 2006). To examine the role of identity dimensions and self-construals for relationship status, the present study provided a cross-sectional examination of the associations between relationship status, identity dimensions, and self-construals.

Our findings indicated that single participants scored higher on exploration in breadth, exploration in depth, and ruminative exploration, and lower on commitment making and identification with commitment when compared with their counterparts in nonmarital romantic relationships. This pattern of results may be associated with a general trend of

Table 2. Standardized Discriminant Function Coefficients and Correlations for the Independent Variables

\begin{tabular}{lccc}
\hline \multicolumn{1}{c}{ Independent variables } & Standardized coefficients & Correlation coefficients & $F$ \\
\hline Exploration in breadth & .53 & .75 & $28.94^{* *}$ \\
\hline Ruminative exploration & .70 & .87 & $19.10^{* *}$ \\
\hline
\end{tabular}

Note. $* * p<.01$. 
postponing the transitions and investment to adult roles, which is observed in many countries, including Poland (Brzezińska \& Piotrowski, 2010b; Fadjukoff, Kokko, \& Pulkkinen, 2007). Such a postponement resulted, for instance, in the rise of the median age of entering marriage and parenthood (Brzezińska \& Piotrowski, 2010b; Fadjukoff et al., 2007) and in the increased number of single adults (Poortman \& Liefbroer, 2010; Such-Pyrgiel, 2014). Being committed in a serious relationship may be perceived as a commitment representing psychological investment (Klimstra et al., 2012) in the domain of romantic relationships. In turn, not being committed in a serious relationship (i.e., single status) might be perceived as a lack of such a commitment. This lack of commitment may be associated with intense exploration of a variety of life alternatives. For instance, this exploration may be associated with a focus on one's own expectations toward a future life partner, with investigating whether the chosen partner represents a suitable partner for a longterm relationship. Furthermore, the results of discriminant function analysis revealed that especially ruminative exploration and exploration in breadth were significant factors for discriminating single and partnered individuals. Thus, in the light of the results obtained we hypothesize that an intensified searching for life alternatives (exploration in breadth) and exploring identity-related issues in a ruminative fashion are important factors that may be associated with prolonged transitions in the area of romantic relationships.

In the current study, single individuals and individuals in nonmarital romantic relationships did not differ in their scores on both self-construals. In light of previous research showing that individuals endorsing relational selfconstruals define the self in terms of close relationships and tend to behave in ways that enhance the development and maintenance of important relationships (Cross et al. 2002), one could expect, however, that some differences would exist between single young adults and young adults in nonmarital romantic relationships with respect to these self-construals. The present lack of differences in both selfconstruals may indicate that despite different orientations toward relationships with others and different ways of managing relationships among individuals of independent and interdependent self (Cross \& Madson, 1997), the achievement of one the fundamental developmental task in young adulthood such as finding a partner/spouse and establishment an intimate relationship with a partner, has the same significance for individuals of interdependent self as well as for individuals of independent self. It may be that self-construal does not influence the significance of developmental task in the domain of marital relationships. This explanation seems to be plausible if we consider individuation and affiliation to comprise universal human motives (Pilarska, 2014), and the need to belong is perceived as a fundamental human motivation (Baumeister \& Leary, 1995). Therefore, individuals of interdependent and independent self may attach the similar importance to finding a romantic partner; however, they may achieve this goal in different manners.

\section{Limitations and Future Directions}

Despite of exploratory nature of the study, the presented results should be interpreted in light of some important limitations. The primary limitation of the present study is its cross-sectional design which prevent us from formulating any casual associations between identity, self-construals, and relationship status. Thus, longitudinal research is needed to provide a better insight into the role of identity and self-construals, both as antecedents and consequences, in the formation and maintaining of single and partnered status. Another limitation of the study is the our sample which consisted only of heterosexual, nevermarried, childless university students, and thus we do not know whether these results could be replicated in sample of older adults or in nonuniversity samples. It is also unclear whether our findings, obtained on individuals at this developmental stage and with history of no marriage, can be generalized to adults of homosexual orientation, being divorced/separated/widowed or having a child/children. It is due to the fact singles are not a unique group and prior studies underscored the importance of distinguishing among subcategories of singles (DePaulo \& Morris, 2005). Therefore, a broader, more representative sample needs to be obtained for future research on these issues. Third, our sample consisted of Polish university students and the lack of a cross-cultural comparison to determine differences between Polish and other (e.g., US) samples in another limitation. Thus, it is possible that the results of this study may not be generalizable to other populations. In the future research, it would be fruitful to perform crosscultural studies as independent and interdependent self are constructs corresponding with distinction between cultural individualism and collectivism (Markus \& Kitayama, 1991), and the culture may clearly influence the content and importance of various an individual's motives and goals (McAdams \& Olson, 2010). Thus, it is plausible that the obtained pattern results would be different in other than Polish culture which is recognized to represent an individualistic society (The Hofstede Centre). Fourth, it would be important to include in further research measurements of intimacy within a given relationship taking into account that in the present study we did not measure intimacy but we understood intimacy in the sense of establishing committed relationships that would lead to marriage (see Sneed, Whitbourne, Schwartz, \& Huang 2012). Finally, in the current study, the internal consistency of the Polish version of Self-Construal Scale (SCS) is acceptable but it is not too high. It is plausible that this nottoo-high reliability of the scale might exert influence on the results obtained in the domain of association between self-construals and relationship status. These internal consistency estimates correspond with other researchers' observations concerning the poor reliability of the SCS (Lu \& Glimour, 2007) and generally validity problems that exist in research involving the use of self-construal scales in cross-cultural research (Levine et al., 2003).

Despite the above-mentioned limitations, the present results indicated that several identity-related process may 
hinder involvement in a romantic relationship. Therefore, the present results provided further support for prior research indicating that postponing the transitions to adult family life may not be positively related to identity development (Fadjukoff, Kokko, et al., 2007). Furthermore, the current investigation rises the need for deeper examination of the role of self-construal for relationship status in young adulthood.

\section{References}

Baumeister, R.F., \& Leary, M.R. (1995). The need to belong: desire for interpersonal attachments as a fundamental human motivation. Psychological Bulletin, 117(3), 497-529. doi: 10.1037/00332909.117.3.497

Bennion, L. \& Adams, G.R. (1986). A revision of the extended version of the objective measure of ego identity status: An identity instrument for use with late adolescents. Journal of Adolescent Research, 1, 183-198

Brzezińska, A.I., Kaczan, Piotrowski, K., \& Rękosiewicz, M. (2011). Odroczona dorosłość: fakt czy artefakt? [Postponed adulthood: fact or artefact?]. Nauka, 4, 67-107.

Brzezińska, A.I., \& Piotrowski, K. (2010a). Polska adaptacja Skali Wymiarów Rozwoju Tożsamości (DIDS) [Polish adaptation of Dimensions of Identity Development Scale (DIDS)]. Polskie Forum Psychologiczne, 15(1), 66-84.

Brzezińska, A.I., \& Piotrowski, K. (2010b). Formowanie się tożsamości a poczucie dorosłości, gotowość do bliskich związków i poczucie koherencji [Identity formation, sense of being adult, readiness to intimate relationships and sense of coherence]. Czasopismo Psychologiczne, 16(2), 265-274.

Carver, K., Joyner, K., \& Udry, J.R. (2003). National estimates of adolescent romantic relationships. In P. Florsheim (Ed.), Adolescent romantic relationships and sexual behavior: Theory, research, and practical implications (pp. 291-329). New York, NY: Cambridge University.

Cieciuch, J. (2010). Struktura czynnikowa Kwestionariusza Stylów Tożsamości Michaela D. Berzonsky’ego. Ile stylów mierzy ISI3? [The factor structure of Micheal D. Berzonsky's Identity Style Inventory. How many styles does ISI3 measure?]. Psychologia Rozwojowa, 15(4), 49-64.

Collins, N. L., Cooper, M. L., Albino, A., \& Allard, L. (2002). Psychosocial vulnerability from adolescence to adulthood: A prospective study of attachment style differences in relationships functioning and partner choice. Journal of Personality, 70(6), 965-1008. doi:10.1111/1467-6494.05029

Cross, S.E., Bacon, P.L., \& Morris, M.L. (2000). The relational-interdependent self-construal and relationships. Journal of Personality and Social Psychology, 78, 791-808.

Cross, S.E., \& Madson, L. (1997). Models of the self: self-construals and gender. Psychological Bulletin, 122(1), 5-37.

Cross, S.E., Morris, M.L., \& Gore, J.S. (2002). Thinking about oneself and others: The relational-interdependent self-construal and social cognition. Journal of Personality and Social Psychology, 82, 399-418.

DePaulo, B., Morris, W. (2005). Singles in society and science. Psychological Inquiry, 2-3, 57-83. doi: 10.1080/1047840X.2005.9682918

Erikson, E.H. (1963). Childhood and society. New York:W.W. Norton.

Erikson, E.H. (1968). Identity, youth and crisis. New York: Norton.

Erikson, E.H. (1980). Identity and the life cycle. New York: W.W. Norton \& Company.

Fadjukoff, P., Kokko, K., \& Pulkkinen, L. (2007). Implications of timing of entering adulthood for identity achievement. Journal of Adolescent Research, 22(5), 504-530. doi: 10.1177/0743558407305420

Fadjukoff, P., Pulkkinen, L., \& Kokko, K. (2005). Identity processes in adulthood: diverging domains. Identity: An International Journal of Theory and Research, 5(1), 1-20. doi: 10.1207/s1532706xid0501_1

Field, A. (2009). Discovering statistics using IBM SPSS Statistics (Third Edition). SAGE Publications Ltd.
Fitch, S., \& Adams, G. (1983). Ego identity and intimacy status: replication and extension. Developmental Psychology, 19(6), 839-845. doi: 10.1037/0012-1649.19.6.839

Gore, J.S., Cross, S.E., \& Morris, M.L. (2006). Let's be friends: Relational self-construal and the development of intimacy. Personal Relationships, 13(1), 83-102. doi: 10.1111/j.1475-6811.2006.00106.x

Klimstra, T.A., Luyckx, K., Branje, S., Teppers, E., Goossens, L., \& Meeus, W.H.J. (2012). Personality traits, interpersonal identity, and relationship stability: Longitudinal linkages in late adolescence and young adulthood. Journal of Youth and Adolescence. Available online from http://link.springer.com/article/10.1007\%2 Fs10964-012-9862-8. doi: 10.1007/s10964-012-9862-8

Lehnart, J., Neyer, F.J., \& Eccles, J. (2010). Long-term effects of social investment: The case of partnering in young adulthood. Journal of Personality, 78(2), 639-670. doi: 10.1111/j.1467-6494.2010.00629.x

Levine, T.R., Bresnahan, M.J., Park, H.S., Lapinski, M.K., Wittenbaum, G.M., Shearman, S.M., Lee, S.Y., Chung, D., \& Ohashi, R. (2003). Self-construal scales lack validity. Human Communication Research, 29(2), 210-252. doi: 10.1111/j.1468-2958.2003.tb0 0837.x

Lodi-Smith, J., \& Roberts, B.W. (2007). Social investment and personality: A meta-analysis of the relationship of personality traits to investment in work, family, religion, and volunteerism. Personality and Social Psychology Review, 11(1), 68-86. doi: 10.1177/1088868306294590

Lu, L., \& Glimour, R. (2007). Developing a new measure of independent and interdependent views of the self. Journal of Research in Personality, 41, 249-257. doi:10.1016/j.jrp.2006.09.005

Luyckx, K., Goossens, L., \& Soenens, B. (2006). A developmental contextual perspective on identity construction in emerging adulthood: Change dynamics in commitment formation and commitment evaluation. Developmental Psychology, 42(2), 366-380. doi: 10.1037/0012-1649.42.2.366

Luyckx, K., Goossens, L., Soenens, B., \& Beyers, W. (2006). Unpacking commitment and exploration: Validation of an integrative model of adolescent identity formation. Journal of Adolescence, 29, 361-378.

Luyckx, K., Schwartz, S.J., Berzonsky, M.D., Soenens, B., Vansteenkiste, M., Smits, I., \& Goosens, L. (2008). Capturing ruminative exploration: Extending the four-dimensional model of identity formation in late adolescence. Journal of Research in Personality, 42, 58-82.

Marcia, J.E. (1966). Development and validation of ego - identity status. Journal of Personality and Social Psychology, 3(5), 551-558. doi: $10.1037 / \mathrm{h} 0023281$

Marcia, J.E. (1980). Identity in adolescence. In J. Adelson (Ed.), Handbook of adolescent psychology (pp. 159-187). New York: John Wiley and Sons.

Markstrom, C.A., \& Kalmanir, H.M. (2001). Linkages between the psychosocial stages of identity and Intimacy and the ego strengths of fidelity and love. Identity: An International Journal of Theory and Research, 1(2), 179-196. doi: 10.1207/S1532706XID0102_05

Markus, H., \& Kitayama, S. (1991). Culture and the self: Implications for cognition, emotion, and motivation. Psychological Review, 98, 224-253.

McAdams, D., \& Olson, B. (2010). Personality development: Continuity and change over the life course. Annual Review of Psychology. Retrieved from: http://works.bepress.com/brad_olson/2

Orlofsky, J.L., Marcia, J.E., \& Lesser, I.M. (1973). Ego identity status and the intimacy versus isolation crisis of young adulthood. Journal of Personality and Social Psychology, 27(2), 211-219. doi: 10.1037/ h0034787

Pals, J.L. (1999). Identity consolidation in early adulthood: relations with ego-resiliency, the context of marriage, and personality change. Journal of Personality, 67(2), 295-329. doi: 10.1111/14676494.00057

Palus, K. (2010). Wybrane psychologiczne uwarunkowania braku partnera życiowego $w$ okresie wczesnej dorostości [The selected psychological factors associated with the lack of a lifetime partner in young adulthhod]. Poznań: Wydawnictwo Wydziału Nauk Społecznych UAM.

Pilarska, A. (2014). Self-construal as a mediator between identity structure and subjective well-being. Current Psychology. doi: 10.1007/ s12144-013-9202-5. Retrieved from http://link.springer.com/article /10.1007\%2Fs12144-013-9202-5 
Poortman, A.R., \& Liefbroer, A C. (2010). Singles' relational attitudes in a time of individualization. Social Science Research, 39(6), 938-949. doi: 10.1016/j.ssresearch.2010.03.012

Rauer, A.J., Pettit, G.S., Lansford, J.E., Bates, J.E., \& Dodge, K.A. (2013) Romantic Relationship Patterns in Young Adulthood and Their Developmental Antecedents. Developmental Psychology. Advance online publication. doi: 10.1037/a0031845

Schachner, D.A., Shaver, P.R., \& Gillath, O. (2008). Attachment style and long-term singlehood. Personal Relationships, 15(4), 479-491. doi: 10.1111/j.1475-6811.2008.00211.x

Schwartz, S.J., Côté, J.E., \& Arnett, J.J. (2005). Identity and agency in emerging adulthood: two developmental routes in the individualization process. Youth and Society, 37(2), 201-229. doi: $10.1177 / 0044118 X 05275965$

Senejko, A. (2010). Inwentarz Stylów Tożsamości (ISI) Michaela D. Berzonsky'ego - dane psychometryczne polskiej adaptacj kwestionariusza [Michael D. Berzonsky' Identity Style Inventory - psychometric data of Polish questionnaire's adaptation]. Psychologia Rozwojowa, 15(4), 31-48.

Simon, R.W., \& Barrett, A.E. (2010). Nonmarital romantic relationships and mental health in early adulthood: Does the association differ for women and men? Journal of Health and Social Behavior, 51(2), 168-182. doi: 10.1177/0022146510372343

Singelis, T.M. (1994). The measurement of independent and interdependent self-construals. Personality and Social Psychology Bulletin, 20(5), 580-591. doi: 10.1177/0146167294205014

The authors have no funding to report.

The authors have no support to report.

The authors have declared that no competing interests exist.
Slany, K. (2006). Alternatywne formy życia matżeńsko-rodzinnego [Alternative forms of married and family life]. Kraków: Zakład Wydawniczy „NOMOS”.

Sneed, J.R., Whitbourne, S.K., Schwartz, S.J., \& Huang, S. (2012). The relationship between identity, intimacy, and midlife well-being: Findings from the Rochester Adult Longitudinal Study. Psychology and Aging, 27(2), 318-323. doi: 10.1037/a0026378

Such-Pyrgiel, M. (2014). The lifestyles of single people in Poland. Procedia - Social and Behavioral Sciences, 109, 198-204.

Terzino, K.A., \& Cross, S.E. (2009). Predicting commitment in new relationships: Interactive effects of relational self-construal and power. Self and Identity, 8, 321-341. doi: 10.1080/15298860802102273

Tesch, S.A., \& Whitbourne, S.K. (1982). Intimacy and identity status in young adults. Journal of Personality and Social Psychology, 43(5), 1041-1051. doi: 10.1037/0022-3514.43.5.1041

The Hofstede Centre. Retrivied from: http://geert-hofstede.com/poland. html

Winefield, H.R., \& Harvey, E.J. (1996). Psychological maturity in early adulthood: Relationships between social development and identity psychological maturity in early adulthood: relationships between social development and identity. The Journal of Genetic Psychology, 157(1), 93-103. doi: 10.1080/00221325.1996.9914848

Zimmer-Gembeck, M.J., \& Petherick, J. (2006). Intimacy dating goals and relationship satisfaction during adolescence and emerging adulthood: Identity formation, age and sex as moderators. International Journal of Behavioral Development, 30(2), 167-177. doi: $10.1177 / 0165025406063636$ 